\title{
A solid tungsten divertor for ASDEX Upgrade
}

\author{
A. Herrmann*, H. Greuner, N. Jaksic, B. Böswirth, H. Maier, R. Neu, S. Vorbrugg \\ and ASDEX Upgrade team
}

Max-Planck-Institut für Plasmaphysik, Euratom Association, 85748 Garching, Germany

\begin{abstract}
The conceptual design of a solid tungsten divertor for ASDEX Upgrade is presented. The Div-III design is compatible to the existing divertor structure. It re-establishes the energy and heat receiving capability of a graphite divertor and overcomes the limitations of tungsten coatings. In addition, a solid tungsten divertor allows investigating erosion and bulk deuterium retention as well as the test of castellation and target tilting. The design criteria, as well as calculations of forces due to halo and eddy currents are presented. The thermal properties of the proposed sandwich structure are calculated with FEM models. After extensive testing of a target tile in the high heat flux test facility GLADIS, two solid tungsten tiles were installed in ASDEX Upgrade for in-situ testing.
\end{abstract}

PACS: 52.55.Rk, 61.30.Hn, 44.30.+v

*Corresponding author: Tel.: +49 8932991388; fax: +49 8932992580.

E-mail address: Albrecht.Herrmann@ipp.mpg.de.

\section{Introduction}

ASDEX Upgrade (AUG) is a mid-size tokamak fusion experiment that was stepwise transformed from a carbon to a tungsten first wall experiment. Starting with the experimental campaign 2007 AUG was operated as a full tungsten experiment. It could be shown that tungsten and ITER like plasma performance are compatible as long as the central heating of the plasma is high enough to suppress tungsten accumulation in the core [1].

The transition from carbon to tungsten was realized by coating fine grain graphite with tungsten physical vapour deposition (W-PVD) up to $4 \mu \mathrm{m}$ thickness in the main chamber and 
with tungsten vacuum plasma spraying (W-VPS) of $200 \mu \mathrm{m}$ thickness at the outer strike line module of the lower divertor where the highest heat load and highest erosion rate of up to $1 \mu \mathrm{m}$ per hour of discharge time was measured. Unfortunately tungsten coatings have a lower heat removing capability compared to pure graphite due to the thermal stress that is induced by high surface temperatures resulting accidentally in a delamination of the coating [2]. The thick coatings in the lower outer divertor were replaced in 2008 by $10 \mu \mathrm{m}$ tungsten deposition by a combination of magnetron sputtering and ion implantation (W-CMSII) [3] to reduce the effect of delamination and tungsten release into the plasma. But, the outer lower divertor is the region with highest sputter yield so that the lifetime of this thin layer is limited to a few campaigns of operation.

This paper investigates the option to install a solid tungsten divertor in ASDEX Upgrade that overcomes the problem of delamination of tungsten coatings under high heat loads and avoid repetitive coatings between campaigns that would be necessary due to the excessive erosion. In addition, it will allow investigating erosion and deuterium retention in bulk tungsten. Furthermore, the new Div-III design offers the option to investigate the effect of castellation and target tilting.

Design criteria and conceptual design of the new Div-III are presented in section 2. Plasma induced forces acting on the solid tungsten divertor will be discussed in section 3 . The thermal load and the heat receiving capability as well as high heat flux (HHF) tests in GLADIS will be discussed in section 4. Finally the status is summarized and a tentative schedule for the implementation of Div-III in AUG is given.

\section{Design criteria and conceptual design}

ASDEX Upgrade is designed as a divertor tokamak with inertially cooled targets clamped on a water cooled support structure. The energy receiving capability of the divertor is given by the heat capacity of the divertor tiles and the tolerated equilibrium temperature. The latter is 
set by the design parameters of the clamping structure to $300{ }^{\circ} \mathrm{C}$ for cyclic loads and $550{ }^{\circ} \mathrm{C}$ for single events. The corresponding total energy load into the divertor is $26 \mathrm{MJ}$ and $48 \mathrm{MJ}$, respectively. Taking into account that about half of the input energy to the plasma is radiated and that the deposited energy is split between inner and outer divertor with a ratio of $1: 2$, the energy limit for plasma heating is $78 \mathrm{MJ}$ and $144 \mathrm{MJ}$, respectively. These parameters allow to use a heating power of $15 \mathrm{MW}$ for the maximum discharge duration of $10 \mathrm{~s}$ or to operate with the installed heating power of $28 \mathrm{MW}$ for $5 \mathrm{~s}$. Therefore, the energy limit of the existing divertor is no limitation for physics investigations as the standard scenarios with typically 1$10 \mathrm{MW}$ plasma heating for up to $5 \mathrm{~s}$ stay far below the upper limit of $144 \mathrm{MJ}$.

More critical is the tolerated heat impact [4] set by thermal parameters of the target material and the maximum allowable surface temperature, that was reduced from about $2500{ }^{\circ} \mathrm{C}$ to $1400^{\circ} \mathrm{C}$ by replacing graphite with tungsten coated graphite during the evolution to a full tungsten experiment. A solid tungsten target would increase the maximum surface temperature at least to about $2800{ }^{\circ} \mathrm{C}$ for carbidized tungsten [5]. The corresponding heat impact values [4] for graphite, tungsten coated graphite and solid tungsten are $31 M W \sqrt{s} / m^{2}, 17 M W \sqrt{s} / m^{2}$ and $48 M W \sqrt{s} / m^{2}$, respectively. Whereas the heat impact limit of $17 M W \sqrt{\mathrm{s}} / \mathrm{m}^{2}$ restricts the discharge duration for high performance plasmas $(>10$ $\mathrm{MW} / \mathrm{m}^{2}$ stationary) to about $2.6 \mathrm{~s}$, the solid tungsten divertor would restore the full discharge duration of $10 \mathrm{~s}$.

A concern is the weight of the divertor that would be about a factor of 10 higher if only the graphite tiles $\left(\rho \approx 1.8 \mathrm{~g} / \mathrm{cm}^{3}\right)$ were replaced by solid tungsten $\left(\rho \approx 20 \mathrm{~g} / \mathrm{cm}^{3}\right)$. Even if the additional weight of about $1.3 \mathrm{t}$ or $80 \mathrm{~kg} /$ sector is only a small contribution to the total weight of the machine of about $52 \mathrm{t}$, the handling of such heavy components during maintenance work would require additional tools and a crane inside the vessel.

Considering these and a few more general aspects, the new Div-III should have: 
- the same energy removal capability as a graphite divertor of about $50 \mathrm{MJ}$

- a heat impact value comparable to the uncoated graphite divertor

- compatibility to the existing support structure for the divertor target plates

- an optimized weight that allows handling with a minimum of in-vessel tools

- induced forces that are compatible to the existing support structure

- a reasonable price

- the potential to be realized in the near future.

A divertor design fulfilling all these conditions is shown in Fig. 1. The $30 \mathrm{~mm}$ thick tungsten coated graphite tiles are replaced by a tungsten graphite sandwich structure, consisting of a $15 \mathrm{~mm}$ thick solid tungsten plate clamped together with a graphite plate of about $15 \mathrm{~mm}$ thickness to the existing cooling structure. Target tilting is realized by shaping the graphite plate rather than the tungsten plate that is flat to minimize the manufacturing effort and to maximize the flexibility of divertor shaping. The advantage of the sandwich structure is the reduction of weight and induced forces. Nevertheless, the weight of the divertor plates is increased from about $8 \mathrm{~kg} / \mathrm{sector}$ to $40 \mathrm{~kg} /$ sector increasing the total weight of a single divertor module from about $30 \mathrm{~kg}$ to $60 \mathrm{~kg}$. A potential disadvantage is the reduced thickness (heat capacity) of the target that is compensated by using TZM as material for the clamping of the sandwich structure, resulting in a higher tolerable equilibrium temperature of $600{ }^{\circ} \mathrm{C}$ and $1000{ }^{\circ} \mathrm{C}$ for cyclic load and single events, respectively. The energy limit becomes for the solid tungsten sandwich divertor 30 and $50 \mathrm{MJ}$ for cyclic and single loads, respectively.

\section{Forces}

The conceptual design of Fig. 1 was the basis for the estimation of forces acting on the tungsten tiles and the divertor support structure. It is expected that the forces due to halo currents to the divertor support structure are not changed because the halo current is dominated by the plasma movement, the divertor contact and the resistivity of the divertor 
tiles plus the resistivity of the support structure that is not changed with the new divertor design. A halo current of $\mathrm{I}=450 \mathrm{kA}$ at a toroidal magnetic field $\mathrm{B}=3.5 \mathrm{~T}$ into the divertor structure with a radial extension of about $1=0.5 \mathrm{~m}$ is considered as a worst case estimation (30\% of the maximum plasma current into the outer lower divertor at the highest magnetic field strength). Typical values are $300 \mathrm{kA}$ at $2.5 \mathrm{~T}$. Static FEM modelling of the divertor support structure for this worst case load of $F_{\text {Halo }}=I B I=450 \mathrm{kA} / 163.5 T 0.5 \mathrm{~m} \approx 50 \mathrm{kN} / \mathrm{sector}$ has shown that the induced von Mises stress is below $100 \mathrm{MPa}$ with a maximum displacement of the divertor support structure of about $0.65 \mathrm{~mm}$. These values are lower in a dynamic-time dependent analysis because of the inertia of the support structure. For the sandwich structure, the active path length of the halo current in radial direction is $1=0.03 \mathrm{~m}$ with a resulting force to a single target tile of $F_{\text {Halo }}=I B l=3.5 \mathrm{kA} 3.5 T 0.03 \mathrm{~m}=0.36 \mathrm{kN}$, the active path length in poloidal direction is about $0.12 \mathrm{~m}$ and the resulting force by a factor of 4 higher. These figures have to be compared to the preload forces given by $2 \times 4$ stacks of disc springs with about $0.6 \mathrm{kN}$ each, fastening the tungsten plate with M5 screws. The resulting preload force of the disc springs is $4.8 \mathrm{kN}$. The force necessary to rupture the screws is in the order of $8 \times 8.5 \mathrm{kN}$ and well above the force induced by halo currents.

More critical are eddy currents induced by the temporal variation of the poloidal and radial magnetic field component during disruptions due to the higher electrical conductivity of tungsten compared to graphite. Here two cases are discussed. (i) the decay of the external magnetic field is faster than the skin time. In this case, the surface current, I, in a flat plate with extensions in toroidal, $\mathrm{t}$, poloidal, $\mathrm{p}$, and radial, $\mathrm{r}$, direction is as large as induced by the external field, $I=p H=p B_{p}^{\text {Plasma }} / \mu_{0}$. This estimation holds for graphite and tungsten because it is independent from the target resistance. The resulting tangential force at the tile surface in presence of a toroidal field, $\mathrm{B}_{\mathrm{t}}$, becomes $F=I B_{t} r=\operatorname{pr} B_{t} B_{p}^{\text {Plasma }} / \mu_{0}$ or about 
$F \approx 0.24 m 0.015 m 3.5 T 0.2 T / \mu_{0} \approx 2 k N$ for the worst case estimation. (ii) the eddy currents are induced by the temporal variation of the poloidal, $\mathrm{B}_{\mathrm{p}}$, and/or radial magnetic field. Because the electrical resistivity, $\rho$, of tungsten is almost a factor 200 lower compared to graphite a significantly higher induced current and a higher force is expected. The force to a rectangular flat plate with extensions in toroidal, $\mathrm{t}$, poloidal, $\mathrm{p}$, and radial, $\mathrm{r}$, direction calculated from Ohms and Faradays law is:

$F_{\text {tot }}=B_{t} \dot{B}_{p} \frac{p}{\rho} \cdot \frac{t / r}{\left(1+r^{2} / t^{2}\right)} \cdot \frac{r^{3}}{12}$

The resulting eddy forces acting on tungsten and graphite target plates as well as on the support structure for comparison is given in Table 1.

The calculated forces due to eddy currents of about $2 \mathrm{kN}$ are well below the preload force of $4.8 \mathrm{kN}$ and are significantly below the rupture force of the fastening screws of about $68 \mathrm{kN}$. The additional force to the support structure can be neglected.

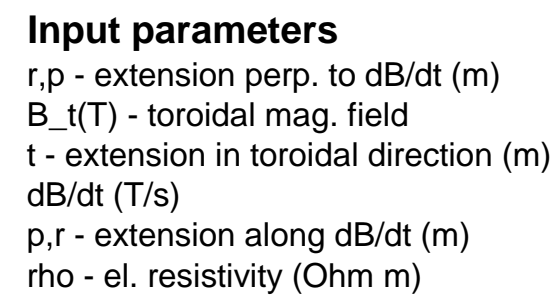

Output

Force (kN):

Torque (Nm)

\begin{tabular}{rrr}
\multicolumn{3}{c}{ poloidal field } \\
Graphite & \multicolumn{1}{c}{ W } & Structure \\
0.015 & 0.015 & 0.1 \\
3.5 & 3.5 & 3.5 \\
0.08 & 0.08 & 0.4 \\
100 & 100 & 100 \\
0.24 & 0.24 & 0.015 \\
$1.0 \mathrm{E}-05$ & $6.0 \mathrm{E}-08$ & $7.0 \mathrm{E}-07$
\end{tabular}

\begin{tabular}{rrr}
\multicolumn{2}{c}{ radial field } \\
W & Structure \\
0.24 & 0.24 \\
3.5 & 3.5 \\
0.08 & 0.32 \\
10 & 10 \\
0.015 & 0.015 \\
$6.0 \mathrm{E}-08$ & $7.0 \mathrm{E}-07$
\end{tabular}

$\begin{array}{lrr}0.01 & 2.03 & 2.35 \\ 0.07 & 11.41 & 88.24\end{array}$

0.34

0.74

$30.24 \quad 66.36$

Table 1 Forces due to eddy currents, induced by a temporal variation of the poloidal or the radial magnetic field. The forces due to eddy currents induced in the divertor structure are given for comparison.

\section{Thermal load and testing}

The thermal behaviour of the sandwich target structure as shown in Fig. 1 was investigated with FEM models and extensively tested in the HHF test facility GLADIS [6]. A combined 
3D FEM modelling (ADINA) of thermal and mechanical loads for a single target tile has shown that the thermally induced strain is uncritical $(<600 \mathrm{MPa})$. 2D FEM modelling was applied to investigate the temperature evolution inside the sandwich structure consisting of the tungsten target, the graphite interface plate and papyex in between tungsten and graphite as well as graphite and the support structure. For a uniform heat flux of $10 \mathrm{MW} / \mathrm{m}^{2}$, the results are shown in Fig. 2 in comparison to the standard target design $(30 \mathrm{~mm}$ graphite $\&$ papyex). The temperature increase during the load phase changes for tungsten at about $3 \mathrm{~s}$ from a square root like to a linear increase. This is earlier compared to the standard target due to the reduced thickness which also causes the slower cooling down at the end of the load phase due to the lower heat capacity. On longer time scales the cooling down is slower for the sandwich structure, because the thermal resistance between the tungsten target and the cooling structure is by about a factor 2 higher compared to the standard divertor. Here the heat transfer through the papyex interface is the limiting figure $\left(2 \mathrm{~kW} /\left(\mathrm{m}^{2} \mathrm{~K}\right)\right)$ and not the graphite plate $\left(5 \mathrm{~kW} /\left(\mathrm{m}^{2} \mathrm{~K}\right)\right)$. Nevertheless, 5 minutes after the end of the discharge, both targets are cooled down to room temperature.

The high heat flux test facility GLADIS was used to perform extensive heat load test of the tungsten tile with the aim to achieve target qualification, to find out the damage level and the consequences of a target overload and finally to increase the surface temperature above the melting limit for carbidized tungsten at about $2800^{\circ} \mathrm{C}$ [5]. The maximum temperatures measured at the end of each heating phase with pyrometers at the surface and with thermocouples at the rear side are shown in Fig. 3.

The tungsten target passes the qualification test of 100 cycles with $10.5 \mathrm{MW} / \mathrm{m}^{2}$ for $3.5 \mathrm{~s}$ without any sign of damage or surface modification. A further increase of the heating phase up to $7.5 \mathrm{~s}$ simulating a higher deposited energy was also passed without damage. A first crack on top of the holes for the mounting rods was observed after a pulse with $23.5 \mathrm{MW} / \mathrm{m}^{2}$ 
for $2.5 \mathrm{~s}$. Nevertheless the heat load was increased up to $30 \mathrm{MW} / \mathrm{m}^{2}$ for up to $1.8 \mathrm{~s}$ and more than 10 pulses at the same position without a malfunction of the target. Inspection of the target at the end of the testing reveals cracks on top of the holes for the mounting rods, and cracks circular around the centre of the heating beam with a diameter of about the full width at half maximum of the beam. No melting was observed at the target. The cracks had no effect on the target clamping. Investigation of crack formation and dynamics is part of ongoing work. Based on this experience it was decided to install two test tiles in AUG. These tiles are now in use for about 700 shots with discharges of $8 \mathrm{~s}$ duration and up to $14 \mathrm{MW}$ plasma heating without any abnormality as could be detected in the video-real-time control system.

\section{Summary and outlook}

The design criteria, the thermal behaviour as well as the compatibility with plasma induced forces of a new solid tungsten divertor (Div-III) were presented. Div-III has the same heat removal capability as a pure graphite divertor and is compatible to the installed plasma heating and the technically possible discharge duration of AUG. The sandwich design results in a slower temperature decay immediately after the end of the discharge but the cool down time to room temperature of about 5 minutes is shorter than the discharge interval. Eddy forces on the clamping induced during disruptions are by about a factor 100 higher compared to graphite but are well below the rupture limit of the fastening screws and also below the preload force of the disc springs. Extensive thermal testing of a tungsten tile was done in the high heat flux test facility GLADIS. The qualification test at $10.5 \mathrm{MW} / \mathrm{m}^{2}$ was passed successfully, a further increase of the heat load and pulse duration up to $30 \mathrm{MW} / \mathrm{m}^{2}$ for $1.8 \mathrm{~s}$ results in cracks on top of the mounting wholes and around the heat load deposition area. These cracks had no influence on the thermal contact and the mechanical stability of the target. Two test targets are installed in AUG for now about 700 discharges. In parallel, study 
of crack propagation by a combination of FEM calculation and experiments in GLADIS was started.

A modification of the clamping, avoiding bore holes inside the tungsten targets and allowing an in-vessel assembly is under investigation and a solid tungsten divertor will be installed in the 2012/13 opening of ASDEX Upgrade.

\section{6. $\quad$ References}

[1] Neu R et al 2009 Phys. Scrip. T138 014038

[2] Herrmann A et al 2009 Phys. Scrip. T138 014059

[3] Ruset C et al 2007 Phys. Scrip. T128 171-174

[4] Herrmann A 2002 Plasma Phys. Control. Fusion 44 883-904

[5] Kurlov A S and Gusev A I 2006 Inorganic Materials 42 121-127

[6] Greuner H et al 2007 J. Nucl. Mater. 367-370 1444-1448 


\section{Figures}

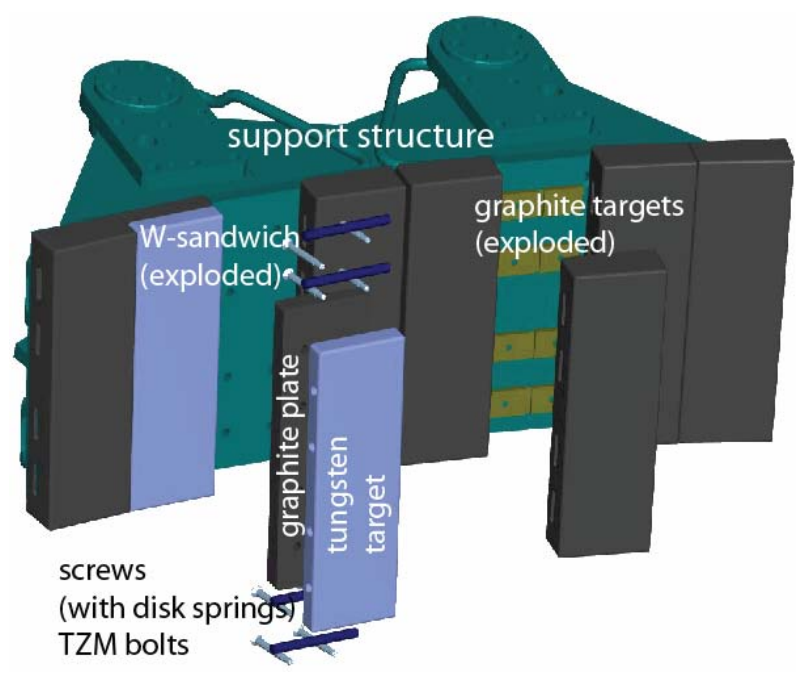

Fig. 1 Design of the tungsten sandwich structure compatible to the installed graphite divertor. Two tungsten sandwich targets, one in an exploded view, surrounded by graphite targets are shown. The sandwich target is clamped by TZM rods in the tungsten tile fixed by screws and disk springs to the support structure. 


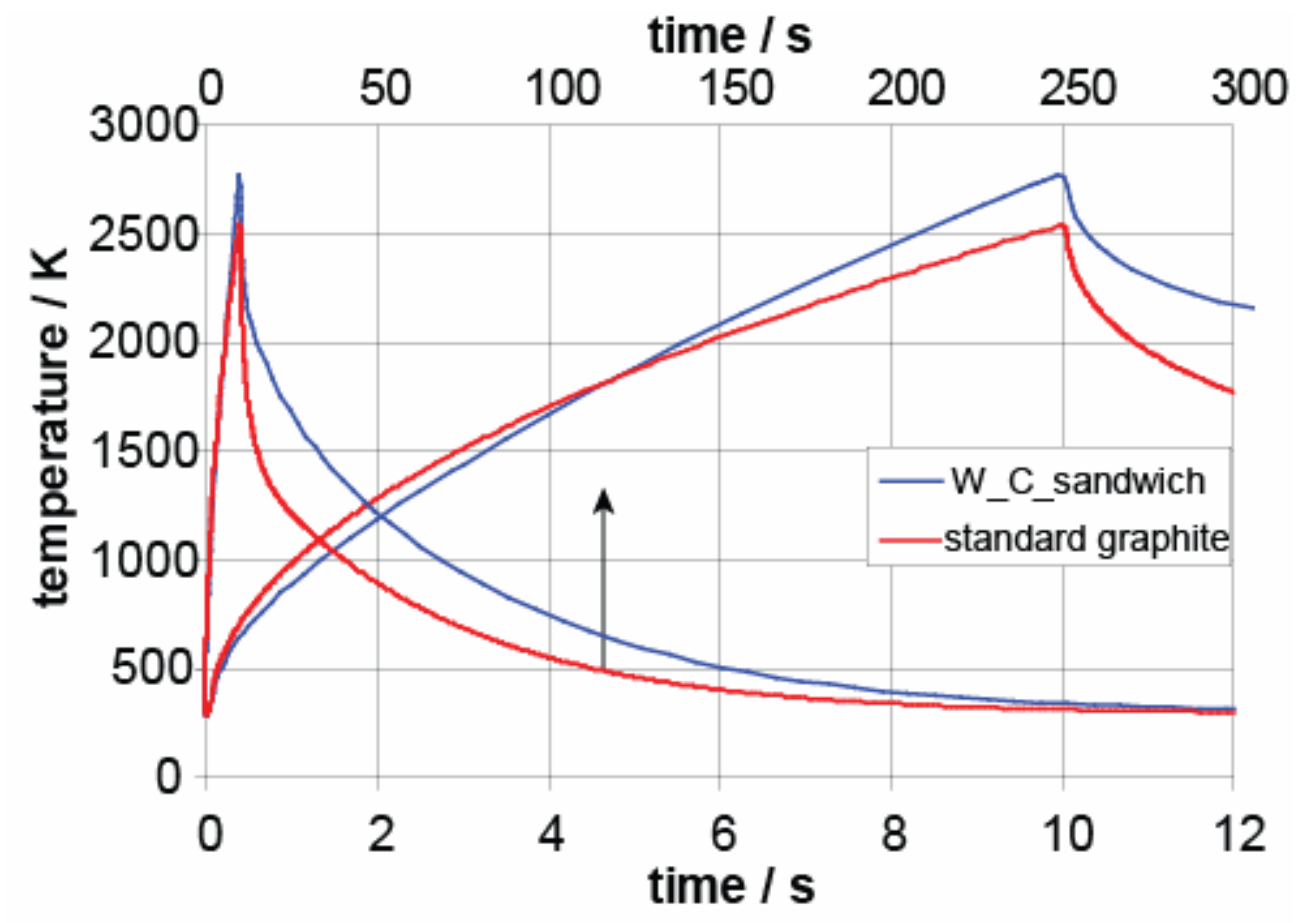

Fig. 2 Comparison of 2D-FEM calculations for the temporal evolution of the surface temperature of a tungsten sandwich and a standard graphite target for a uniform surface heat load of $10 \mathrm{MW} / \mathrm{m}^{2}$ for 10s. The sandwich structure consists of $15 \mathrm{~mm}$ thick tungsten and graphite, respectively, with papyex as interface. 


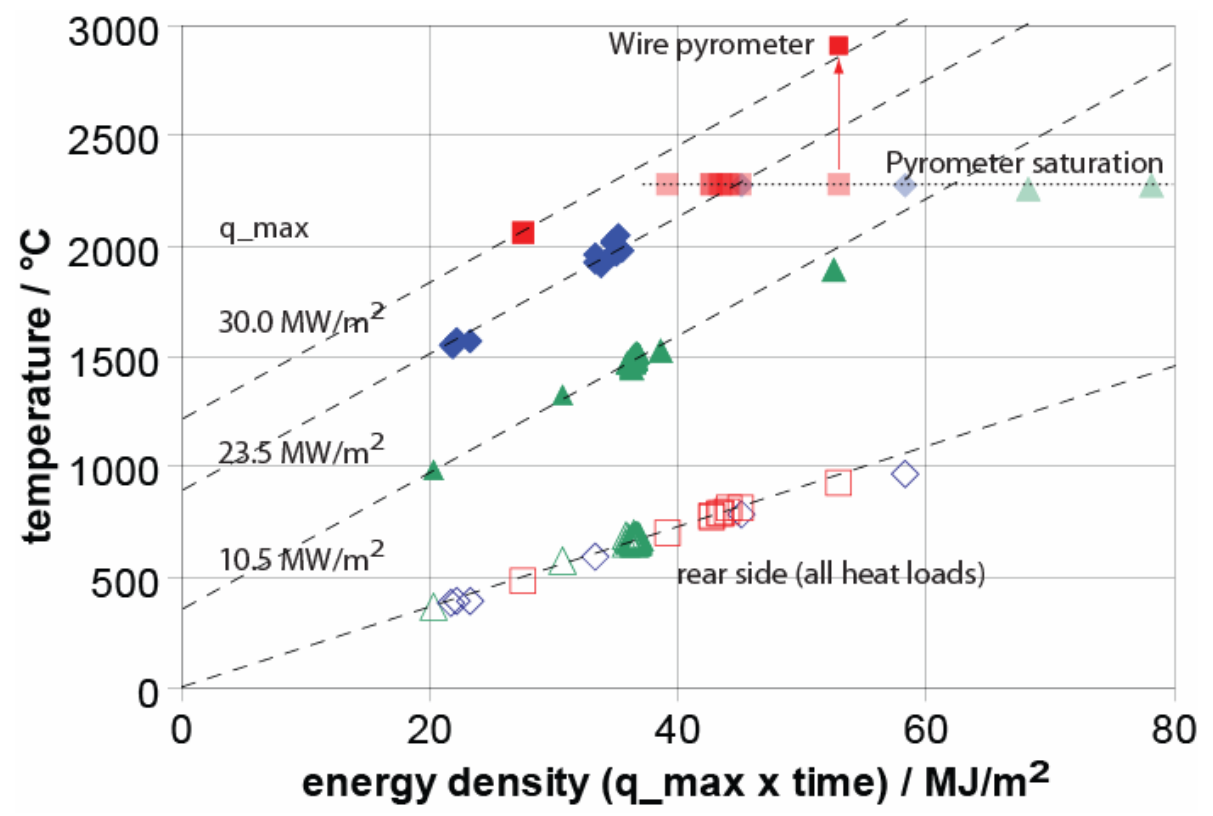

Fig. 3 Summary of the HHF tests in GLADIS. The rear side temperature increases with the deposited energy density independent on the surface heat flux (open symbols). Whereas the surface temperature depends on the heat flux as indicated in the figure (closed symbols). 